\title{
Extralobar sequestration with anomalous pulmonary artery return or patent ductus arteriosus?
}

\author{
Daniel Pop, MD, ${ }^{a}$ Nicolas Venissac, MD, ${ }^{\text {a }}$ Christophe Perrin, MD, ${ }^{b}$ Francesco Leo, MD, ${ }^{a}$ Bernard Padovani, MD, ${ }^{c}$ and \\ Jérôme Mouroux, MD, ${ }^{a}$ Nice, France
}

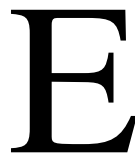
xtralobar sequestration represents a bronchopulmonary foregut malformation with no connection to the bronchial system. Its coexistence with other pulmonary malformations is widely reported, ${ }^{1}$ but association with the agenesis of the pericardium is exceptional. ${ }^{2}$ Moreover, the blood supply is ensured by systemic arteries and the vascular return by the pulmonary or systemic veins or, rarely, a pulmonary artery. ${ }^{3}$ We found no case of abnormal pulmonary artery trunk return or association with patent ductus arteriosus, such as ours.

\section{Clinical Summary}

A 30-year-old woman was admitted to the emergency department with intense pain in the left side of the chest, dry cough, shortness of breath, and fever (temperature, $38.6^{\circ} \mathrm{C}$ ). Six weeks earlier, she had a surgical intervention (with good recovery) for acute peritonitis complicating a neglected appendicitis. In addition to the abdominal findings, preoperative computed tomography (CT) revealed a left pleural reaction and an anterior cystic opacity in the left midpulmonary field.

At physical examination, the left pleural effusion was evident. Hematology showed $11,500 / \mu \mathrm{L}$ white blood cells with C-reactive protein of $205 \mathrm{mg} / \mathrm{L}$ (normally $<5 \mathrm{mg} / \mathrm{L}$ ). Blood gas and electrocardiographic results were normal.

The chest $\mathrm{x}$-ray film showed a left pleural effusion. The CT scan indicated 2 neighboring pouches: the first is in the anterior midthoracic field, and the other is posterior, in the costodiaphragmatic recess. A chest tube was put in place, with use of intrapleural fibrinolytic agents (urokinase, 100,000 IU/d, for 5 days) and oral antibiotics. The cytology of the pleural liquid showed $40,000 / \mu \mathrm{L}$ altered leukocytes, but no bacteria were found (cultures made confirm the absence of germs). Two weeks later, only the anterior lesion was present. A new CT scan showed a thin wall lesion going from the aortopulmonary window to the anterolateral thoracic wall. It was $85 \mathrm{~mm}$ in the great axis, with homogenous liquid inside. The contrast enhancement revealed a pathologic artery from the internal surface of the isthmic aortic region passing below the aortic cross to this lesion (Figure 1). A second 32-mm cystic

From the Thoracic Surgery Department, ${ }^{\mathrm{a}}$ the Pneumology Department, ${ }^{\mathrm{b}}$ and the Radiology Department, ${ }^{\mathrm{c}}$ Pasteur Hospital, Nice, France.

Received for publication Jan 5, 2005; accepted for publication Feb 8, 2005.

Address for reprints: Daniel Pop, MD, Thoracic Surgery Department, Pasteur Hospital-Building H, 30 Avenue de la Voie Romaine, 06002 Nice, France (E-mail: danielpopch@yahoo.com).

J Thorac Cardiovasc Surg 2005;130:903-4

$0022-5223 / \$ 30.00$

Copyright $\odot 2005$ by The American Association for Thoracic Surgery

doi:10.1016/j.jtcvs.2005.02.042

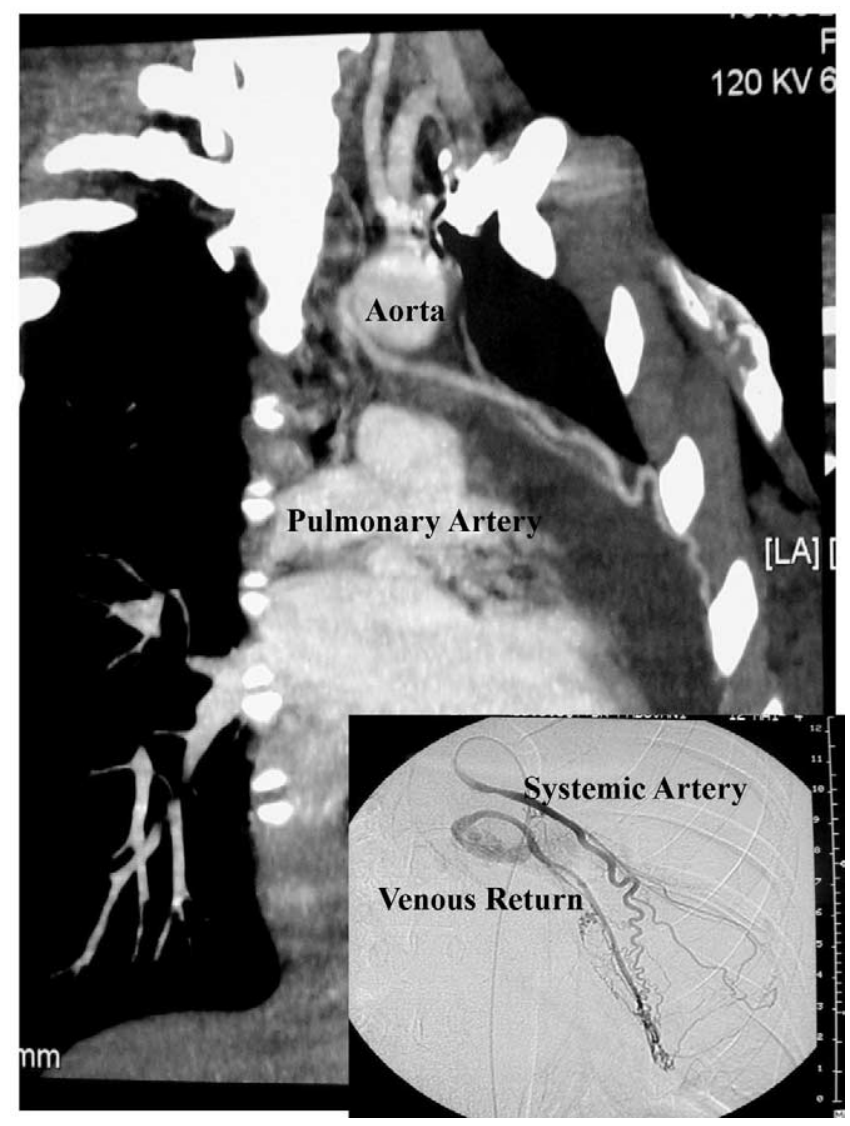

Figure 1. CT chest scan and aortogram showing the systemic artery and pulmonary artery return.

lesion was also noted in the left cervicomediastinal paratracheal position.

A preoperative aortogram confirmed the nourishing vessel. The venous return was made in the pulmonary artery (Figure 1).

A posterolateral thoracotomy was performed. After the complete liberation of the lesion, a partial upper pericardial defect was seen. The hilum of the cystic mass was found in the aortopulmonary window: the systemic artery was from the aortic cross, and the bronchial structure blind ended near the left tracheobronchial angle (Figure 2). The return was done in the pulmonary artery trunk division, and no arterial ligament was identified. The lesion was resected, and the histopathology confirmed the extralobar sequestration. The pericardial defect was too small to be restored, and the cervicothoracic bronchogenic cyst was inaccessible with this approach. The postoperative period was uneventful. 


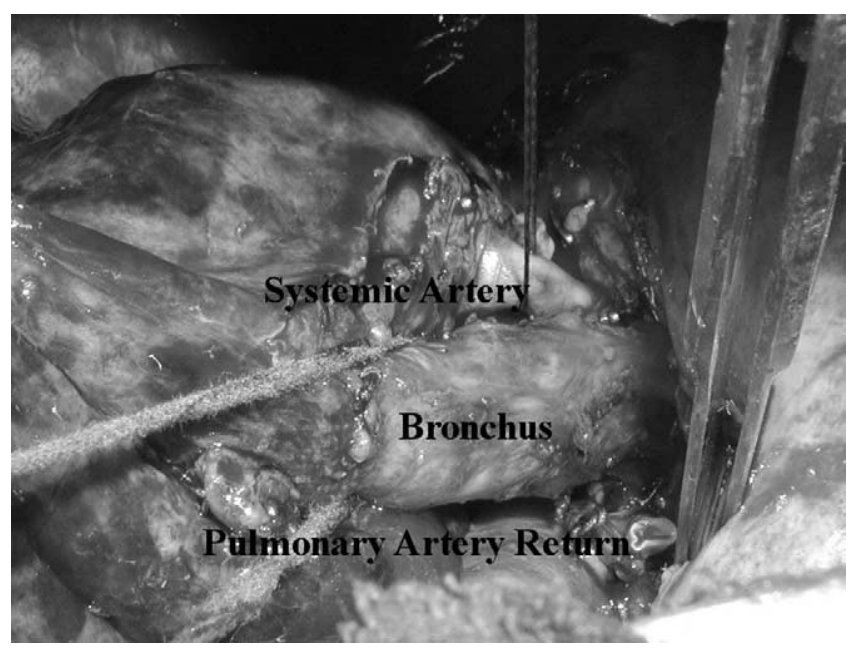

Figure 2. Perioperative view of the extralobar sequestration in the aortopulmonary window: the pulmonary artery return was ligatured. Ao, Aortic arch; $P A$, pulmonary artery.

\section{Discussion}

Extralobar pulmonary sequestration remains a rare anomaly that could coexist with a variety of malformations. ${ }^{1}$ In our patient extralobar pulmonary sequestration was associated with a bronchogenic cyst on a different level, with no communication between them and a partial agenesia of the left pericardium. In fact, during embryonic development, malformations can appear at any level or in different levels of the primary foregut either from (1) separation of embryonic forming cells because of adhesion of other organs or (2) a separate outpouching. ${ }^{4}$

First, the pulmonary vascular development is in direct relationship with the lung bud system. In the 4 to 6 weeks of embryonic development, the first supply of systemic capillaries from the primitive aorta is gradually replaced by the pulmonary artery system. If the systemic plexuses do not regress, an anomalous arterial supply might develop and exert traction on the ectopic pulmonary tissue, leading to sequestration. Pulmonary oligemia can be a responsible factor for either systemic artery persistence or reestablishment of pulmonary-splanchnic collaterals. ${ }^{5}$ Second, the ductus arteriosus develops in the same embryonic period. An abnormal bud pouching can push the arterial systemic-pulmonary connection, provoking a patent ductus arteriosus or developing an abnormal network of it. Both of these theories might match perfectly with our case.

In our opinion, the pulmonary sequestration represents an indication for surgical intervention. In addition to the classic complications (infection, mediastinal compression, intracystic hemorrhage, and perforation), cardiovascular events can occur. Ransom and associates ${ }^{6}$ reported 1 case and reviewed another 2 cases of cardiac consequences arising from important shunting of unknown sequestration. They support immediate surgical intervention. Our patient had a veritable left-to-right systemic-pulmonary shunt with no heart consequences. Therefore, surgical indication was legitimate in an effort to prevent right cardiac pursuit.

In consequence, early recognition of extralobar sequestration would lead to immediate and proper surgical intervention to prevent important complications.

\section{References}

1. Savic B, Birtel FJ, Tholen W, Funke HD, Knoche R. Lung sequestration: report of seven cases and review of 540 published cases. Thorax. 1979;34:96-101

2. Porte HL, Masouille DG, Lebuffe GR, Wurtz AJ. A unique congenital mediastinal malformation. Ann Thorac Surg. 2001;71:1703-4.

3. Schmitzberger R, Gassner I, Ausserer B. [A rare case of venous drainage in intralobar pulmonary sequestration]. Pneumologie. 1990;44:787-9.

4. Skandalakis JE, Gray SW, Symbas P. Pulmonary circulation. In: Mitchell $\mathrm{CW}$, editor. Embryology for surgeons: the embryological basis for the treatment of congenital anomalies. Baltimore, Md: Williams and Wilkins; 1994. p. 451-90.

5. Flisak ME, Chandrasaker AJ, Marsan RE, Ali MM. Systemic arterialization of lung without sequestration. Am J Radiol. 1982;138:751-3.

6. Ransom J, Norton J, Williams G. Pulmonary sequestration presenting as congestive heart failure. J Thorac Cardiovasc Surg. 1978;76:378-80. 